\title{
Pragmatic Information in Two English Monolingual Learners' Dictionaries
}

\author{
By: \\ Dr. Miranda Mohamed Khamis EL-Zouka \\ Associate Professor \\ English Department \\ Faculty of Arts \\ Alexandria University \\ Damanhour Branch
}




\section{(1) Introduction}

English monolingual learners' dictionaries present different kinds of linguistic information, such as semantic, syntactic, stylistic, and pragmatic. An important kind of this information is pragmatic information. It is of special importance because it maintains suitable and comprehensible communication between speakers/writers. Usually if users make any mistake in pragmatic information, miscommunication takes place. Thus, users have to be very cautious when using language in real life situations, and one place they can obtain knowledge about correct pragmatic use of language is dictionaries. Therefore, it is important to analyse how dictionaries present pragmatic information about language.

\section{(2) Aims and Methodology of the Study}

The study aims at providing an analysis of two monolingual learners' dictionaries; namely Macmillan English Dictionary for Advanced Learners (MEDAL) and Oxford Advanced Learners' Dictionary (OALD).These two dictionaries have been chosen because they have a well-known world-wide reputation as they are published by two famous publishing houses, namely Macmillan Publishers Limited and Oxford University Press, respectively. They are also widely used by English language learners.

To analyse the pragmatic information in the two dictionaries in question at the lexical, sentential, and discourse levels, the entries, or the relevant parts of entries that contain pragmatic information, of twenty six headwords have been studied in the two dictionaries under investigation. This is done to examine how much pragmatic information at each level is provided in these two dictionaries as well as the lexicographic methods used to present this kind of information. The analysis will demonstrate the strong and weak points regarding the presentation of pragmatic information in the two dictionaries under investigation.

\section{(3) Theoretical Background}

Pragmatic information in dictionaries deals with the representation of speakers' attitudes towards reality, the message, and/or the interlocutor, which is encoded in linguistic signs as units of language system. (Apresyan, 1988 as cited in Burthanov, 2003:103). Svensen (1993:6) indicates that pragmatic information in dictionaries deal with the occurrence of words and their combinations in different dimensions of language. Such information is provided by means of subject field and register labels. Moreover, Hartmann and James (2000:111) define pragmatic information in dictionaries as "information on the sociocultural rules of speaking". It has exponents as paralinguistic features such as tone, intonation, gesture, pitch as well as the choice of vocabulary 
in terms of politeness and formality conventions, which can reinforce or contradict the speakers' intended meaning. It is obvious from the previous definitions that they confine pragmatic information only to the lexical level.

Nobuyuki (1981) states that pragmatic information can be studied in relation to three different components of language use. The first is time, place of language and social status of the language user. The second is age, gender, and occupation of the language user. The third is mode (spoken or written), audience, and register.

Concerning the different kinds of pragmatic information in dictionaries, Hartmann (1983:111) indicates that they are as follows:

1- Speech habits of the individuals (idiolects)

2- Orientation by communicative purpose (speech acts)

3 - Field, mode, and role specialization (register)

4- Texture and formality specialization (style)

5- Speech habits of a social group (sociolects)

6- Chronological stages ( temporality)

7-Culturally favoured norms (standard and non standard usage)

8- Interlingual exchanges (creoles)

Landau (1991:175) also maintains that the most common kinds of pragmatic information in dictionaries are: currency or temporality, frequency of usage, field labels, geographical variations, insult and offence, slang, style, and restricted or taboo use. He also indicates that pragmatic information specifies the limitations in the use of words according to time, place, and/or circumstances of the communicative interaction. Furthermore, Quian (1995) states that there are three kinds of pragmatic information. The first is referential pragmatic information that can be manifested in deixis. The second is textual pragmatic information that is expressed through discourse markers. The third is socio-pragmatic information which is related to the speaker's attitude and intention, as well as the relationship between the speaker and the listener. These three kinds of pragmatic information are indicated in dictionaries using equivalent definitions, subject and register labels, as well as usage notes.

In recording pragmatic information, lexicographers must be objective and record various uses of the included headwords as they are actually used by people. Therefore, it becomes clear that investigating pragmatic information in lexicography is inseparable from the category of usage. McArthur (1998:626) defines usage as "the way in which the elements of language are customarily used to produce meaning, including accent, pronunciation, spelling, punctuation, words, and idioms." 
Pragmatic information can be found in any part of the entry as in the definition itself, or marked using various usage labels such as $B r E$, formal, slang, etc. They can also be indicated separately in usage notes. These are written in the form of descriptive explanations in the entry as a framed article (Burthanov, 2003:104). Pragmatic information can also be found in cross-references between entries where links among various entries are established because they share some aspect of meaning or to indicate differences between them, and also to indicate various kinds of linguistic information, such as pragmatic, syntactic, etymological, and semantic information.

Pragmatic information is found on the lexical, sentential, and discourse levels. At the lexical level, pragmatic information exists in six kinds of vocabulary items. These are address forms, discourse markers, hedges, speech act verbs, modal verbs, and context markers.

Lyons (1979:76) indicates that address forms are a kind of social deixis which concerns "that aspect of sentences which reflect or establish or are determined by certain realities of the social situation in which the speech act occurs." Moreover, Levinson (1983:89) mentions that social deixis encode the social identities of participants, or the social relationship between them or between one of them and the persons and entities referred to. He also maintains that many aspects of language usage depend on these relations such as pronouns indicating politeness and titles of address.

Address forms can be divided into social address forms that show the relationship between participants in a given social event, such as $M r$., Mrs., address forms between family members and relatives such as uncle, mom, and forms of love and friendship, such as baby sweetheart, and finally honorifics that indicate a higher social status (Yule, 2008:10).

Discourse markers are words and phrases that indicate the relationship between an utterance and the prior discourse (Levinson, 1983:87). Examples of discourse markers are but, and, therefore, and all in all. They indicate how the sentence/utterance that contains them is a response to the same portion of the prior discourse (Levinson, 1983:88). These discourse markers show the relationship between utterances, for example, and is used to show additions, as in Mary wanted to eat fish and John wanted chicken. Discourse markers are of three main kinds. The first kind is discourse markers that occur at the beginning or at the end of a sentence. The second kind is discourse markers which indicate the development of discourse. This kind is subdivided into four kinds, which are: elaborative markers, contrastive markers, inferential markers, and topic change markers. Finally, the third kind is markers that indicate a speaker's attitude and tone (Brinton, 1996: 279-81). 
A hedge is a linguistic tool used to lessen the impact of an utterance. Hedges are cautious notes expressed about how an utterance is to be taken. They indicate that what is said may not be totally accurate. For instance, as far as I know is used when giving information (Yule, 2008:38, 130). They can be used intentially or unintentailly in spoken rather than written discourse. They are adjectives and adverbs, such as probably, possibly, etc. They can also be formed of clauses, such as, as far as I know, I think, I believe, this is confusing but, etc... Hedges help speakers and writers communicate more precisely the degree of accuracy of what they say or write. They also allow speakers to sound more polite, especially when disagreeing with someone or when refusing a request.

Speech act verbs or performative verbs are those that a speaker uses to get the hearer to do something. Examples of these verbs are refuse, apologize, complain, permit, etc... These verbs perform various acts such as refusing, apologizing, complaining, permitting, etc.... The extent to which direct expressions are allowed and considered polite depends on culture-specific interactional rules.

Modal verbs indicate the attitude of the speaker/writer towards the state or event expressed by another verb. (Richards et al, 1992:1790). They indicate the speech act performed by an utterance or sentence in which the modal occurs. For instance, may and will are used to ask for permission or ask for a request, respectively. The past tenses of these modal verbs indicate a more polite attitude on the part of the speaker. Azar (1989:70, 110-12) clarifies that, generally, when expressing politeness, opinions, making recommendations or suggestions or simply giving advice, modal verbs can be used, such as :

Can/Will you help me? (A simple request)

Could/Would you help me? (A more polite request)

Context markers are words and expressions that are only used in certain contexts. For example, some words are used only in specific regions, such as the distinction between British and American English. Others are formal, such as foe, and others are informal, as guy. There are also other words that are technical, figurative, archaic, poetic, etc....These words can be grouped together as information about the style of the included headwords in dictionaries.

Pragmatic information on the sentential level involves the function of a given sentence or utterance. This happens in the case of proverbs, such as $A$ bird in the hand is worth ten on the bush, which is used to advise somebody to be satisfied with what he/she has. Proverbs and fixed expressions are usually found in separate sections in dictionaries. Emphatic structures using do can also be used to express politeness, 
surprise, etc..., as in Please do come in. Pragmatic information on the sentential level can also be found in tense and aspect. As for tense, the past tense of some verbs, such as wonder is usually considered very polite. Concerning aspect, the continuous aspect can soften the tone of speaking, as in:

\section{I was thinking if she could come and help me tomorrow.}

The passive voice can also be used to avoid direct orders and sound more polite, as in:

\section{Clean the room. (Direct order)}

Your room should be cleaned. (A more polite order)

Pragmatic information can also be found on the discourse level. It includes the choice of topic, cultural background, and conversational speech act pairs. As for the choice of topics, a distinction can be made between general topics, such as daily problems, political, economic, and social issues, as well as sensitive and taboo topics concerning religion and sex. As for cultural background, different cultures have different views concerning general, sensitive, and taboo topics. However, what is considered a common topic in a given culture can be sensitive or taboo in another and vice versa. Finally as for conevential speech act pairs, these are used in instances, such as when somebody receives a compliment, the other speaker says, "thank you." These pairs include various acts, such as greeting, apologizing, refusing, etc. Dictionaries indicate, in the entries of some headwords, information about the cultural background of some words using labels, such as taboo, offensive to indicate to users that they must be cautious when using these words. Dictionaries do not normally indicate information about neither the choice of topics nor convential speech act pairs. Only in the case of the latter, some pairs are included in the entries in usage notes of speech act pairs.

\section{(4) Pragmatic Information in English Monolingual Learners'}

\section{Dictionaries}

The previously mentioned different kinds of information are included in English monolingual learners' dictionaries either in the microstructure or the macrostructure of dictionaries. The former refers to the structure of the individual dictionary entries, while the latter refers to the arrangement of the entries of dictionaries (Svensen, 1993: 210, 223). The macrostructure of dictionaries includes the front, middle, and back matters. Information concerning pragmatic information, how it is 
included in dictionaries, and how users can find them in dictionaries can be found in any of the previous sections.

In OALD, nothing is included in the front, middle, and back matters about the treatment of pragmatic information in it. Only in parts of the entries of some of the included headwords, there are subject and register labels. However, in MEDAL, in the middle matter of the dictionary, there is a "language awareness" section, and one of the points discussed is "pragmatics" written by Dr. Joanna Chanell. She first discusses what is meant by pragmatics and its importance to language users. Next, she discusses pragmatic information in the dictionary, and the different kinds of pragmatic information discussed in MEDAL, which is information about:

Language functions or speech acts

Politeness

Attitudes and feelings

Vague language

There is also information about the treatment of pragmatic information in MEDAL can also be found in some usage notes sections of some of the included headwords as will be illustrated in the following section.

\section{(5) Analysis}

\section{(5.1) Pragmatic Information at the Lexical Level}

It has been mentioned that pragmatic information at the lexical level includes six kinds of words, namely address forms, discourse markers, hedges, speech act verbs, modal verbs, and context markers. Samples form each lexical group are provided form both MEDAL and OALD.

\section{(5.1.1) Address Forms}

\section{(5.1.1.1) Social Address Forms}

The two words chosen for analysis are Mr. and Mrs.

\section{In MEDAL:}

Mr. 1- used in front of the name of a man when talking politely to him about him. Mr. is a short form of mister...1a. a title used before the name of a man's position when speaking to him....

Mrs. A polite or formal title used in front of the name of a woman who is married, when talking to her about her. 


\section{In OALD:}

Mr. (BrE) (also Mr. NAmE, BrE) abbr 1 a title that comes before a man's family name, or before his first and family names together...2 a title used to address a man in some official position....

Mrs. (BrE) (also Mr. NAmE, BrE) abbr (BrE) (also Mr. NAmE, BrE) abbr. a title that comes before a woman's family name or before her first name and family names together.

It can be noticed form the entries of $M r$. and Mrs. that only MEDAL indicates that they are used when talking politely about a man and a woman, respectively. It also adds in the entry of Mrs. that it is a polite and a formal title. The pragmatic information provided is found as part of the definition, and shows the interpersonal relationship between the addressor and the addressee. OALD does not indicate this kind of pragmatic usage.

\section{(5.1.1.2) Address Forms between Family Members and Relatives}

The two words chosen for analysis are dad and daddy.

In MEDAL:

Dad...informal...your father.

Daddy...informal...your father. This word is used mainly by children or when speaking to children....

In OALD:

Dad ...informal (often used as a name) father....

Daddy... used especially by and to young children, and often as a name, to mean 'father'...

The two dictionaries mention that $d a d$ is an informal word in the form of a usage label. Both dictionaries provide pragmatic information as part of the definition about users of the word daddy which is that it is used by young children and in conversations with them. Also, only MEDAL mentions that it is an informal word also using a separate usage label.

\section{(5.1.1.3) Address Forms of Love and Friendship}

Baby and sweetheart are taken as examples of such address forms.

\section{In MEDAL:}

Baby...4 spoken used for talking to someone you love, especially to someone you are in a romantic relationship with or to your child....

Sweetheart...1 spoken used for talking to someone you love...

2 used especially by men for talking to a woman whose name they do not know.

Many women find this use offensive.... 


\section{In OALD:}

Baby...4 (Slang, especially NAmE) a word used to address sb, especially your wife, husband, or lover, in a way that expresses affection but that can be offensive if used by a man to a woman he does not know.

Sweetheart...1 used to address sb in a way that shows affection.. 2 ...(becoming old fashioned) a person with whom $\mathrm{sb}$ is having a romantic relationship....

In the entry of baby, OALD labels it as slang. It indicates in the definition that it expresses affection, but "can be offensive" if a man uses it to address a woman he does not know, while MEDAL does not include any of this information and only labels it as spoken. In the entry of sweetheart, both dictionaries mention in the definitions, in the first sense, that it shows affection and love. Only MEDAL labels this use as spoken. Moreover, only MEDAL indicates in the second sense, as part of the definition, that it is used by men to talk about a woman they do not know, and that women find this use offensive. So, the pragmatic information provided regarding this particular sense indicates the undesirable effect this word can have on the addressee. The two dictionaries use usage labels regarding some of the senses. MEDAL uses the label spoken for the first sense, and OALD uses the label becoming old fashioned for the second sense.

\section{(5.1.1.4) Special Address Forms}

The two words chosen as examples of this kind of address forms are highness and honour.

\section{In MEDAL:}

Highness... used for talking to or about a king, a queen, prince, or princess.

Honour...Phrases...Your honour used when talking to a judge in a court of law....

In OALD:

Highness... a title of respect used when talking to or about a member of the royal family...

Honour... JUDGE/MAYOR 9... His/Her/Your Honour... a title for respect used when talking to or about a judge or a US Mayor....

In the two entries, MEDAL does not include any kind of pragmatic information. However, only OALD clarifies in the definition that both are titles of respect. Thus, there is an indication of the interpersonal relation between the addressor and the addressee when using these two words. 


\section{(5.1.2) Discourse Markers}

Discourse markers are of three main kinds as indicated before, namely discourse initiating and ending markers, discourse developing markers, and markers of a speaker's attitude and tone. The second kind can be subdivided into elaborative markers, contrastive markers, inferential markers, and topic-change markers. The following are examples of sections of entries of some discourse markers in the two dictionaries under investigation analysed in terms of the pragmatic information found in these sections.

\section{(5.1.2.1) Discourse Initiating and Ending markers}

The two entries of anyway and $o k$ are taken as examples of discourse initiating and ending markers.

\section{In MEDAL:}

Anyway...3 used for changing the subject used when you are changing the subject of a conversation back to what you were talking about earlier...

4 Used for ending a conversation used for ending a conversation or for showing that you have come to the end of what you are telling someone....

O.K. ...1 a used for asking if someone agrees with what you have just said, or if he or she understands... 2 used when you want to start talking about something or want to continue discussing it after a pause...3 used when you want someone to stop arguing with you or criticizing you. The word after shows that you accept what they are saying but do not think it is important..

In OALD:

Anyway...3 used when changing the subject of a conversation, ending the conversation, or returning to a subject.

O.K. ...2 used to attract sb's attention or to introduce a comment...3 used to check that $\mathrm{sb}$ agrees with you or understands you...4 used to stop people arguing with you or criticizing you...

The two dictionaries mention, as part of the definitions, some of the discourse functions of anyway. It is "used when changing the subject of a conversation," and when returning to it or when ending it. OALD, however, is more concise as it states this information in a single sense, but MEDAL states it in the two senses. As for $o k$, only MEDAL states that it is used when one wants to start talking about something. However, as for the rest of the pragmatic information, both dictionaries mention other functions, such as to attract attention, to check that the addressee agrees with the speaker, and when one wants to stop arguing. However, MEDAL adds extra information concerning the last uses which is that $o k$ shows that one accepts, although not convinced with what others say. 


\section{(5.1.2.2) Discourse Developing Markers}

\section{(5.1.2.2.1) Elaborative Markers}

Moreover is an elaborative marker defined as follows in the two analysed dictionaries:

\section{In MEDAL:}

Moreover...formal...used for introducing an additional and important fact that supports or emphasizes what you have just said.

\section{In OALD:}

Moreover...formal used to introduce some new information that adds to or supports what you have said previously.

The two dictionaries mention that it is formal and used to add information that supports what one has said.

\section{(5.1.2.2.2) Contrastive Markers}

The contrastive marker however is defined as follows in the two dictionaries under investigation:

\section{In MEDAL:}

However...1 used for giving surprising information used when you are saying something that seems surprising after your previous statement or that makes your previous statement seem less true...

2 used for changing the subject used when you are changing the subject.... In OALD:

However...3 used to introduce a statement that contrasts with something that has just been said....

The two dictionaries state in the definition that however is used at the beginning of a statement that contrasts with the previous one. Thus, in this case, it indicates surprising information. However, MEDAL adds another function in a separate sense, which is that it is used to change the subject. So, it is also a topic-change marker.

\section{(5.1.2.2.3) Inferential Markers}

Therefore is an inferential marker, which is defined as follows in the two dictionaries under investigation:

In MEDAL:

Therefore is used as a way of showing how a sentence or clause is related to what has already been said.

Therefore...as a result of the reason that has just been mentioned.... 
In OALD:

Therefore ... used to introduce the logical result of something that has just been mentioned

Unlike MEDAL, OALD is more explicit as it clearly mentions that it shows the result of what has been said. MEDAL does not include this information. It only shows the relationship between the sentence in which it occurs and the previous one.

\section{(5.1.2.2.4) Topic-change Markers}

Anyhow is taken as an example of topic-change markers, and it is defined as follows in the two dictionaries in question:

In MEDAL:

Anyhow...3 used for limiting a statement spoken Used when adding a statement that limits what you have just said...

5 used for changing the subject spoken used when you are changing the subject of a conversation back to what you were talking about earlier.

6 used for ending a conversation spoken used for ending a conversation, or for showing that you have come to the end of what you were telling someone....

\section{In OALD:}

Anyhow...3 used when changing the subject of a conversation, ending the conversation, or returning to a subject...

4 used to correct or slightly change what you have said....

Both dictionaries indicate that anyhow is used when changing the subject of a conversation or ending it. Only OALD mentions that it is used to return to a subject of a given conversation. Also, OALD uses the usage label spoken to mark the three senses of anyhow. In addition, only MEDAL clarifies that it is used to limit a statement. Therefore, it is clear that the two dictionaries differ in the pragmatic information they include in the entries of the headword anyhow.

\section{(5.1.2.3) Markers of Speaker's Attitude and Tone}

The two entries of actually and well are taken as examples of markers of a speaker's attitude and tone in the two analysed dictionaries.

\section{In MEDAL:}

Actually...1 used for emphasizing what is really true or what really happened...

2 used for emphasizing that something is surprising...

3 spoken used when correcting what someone has said or thinks or what you yourself have said....

Well...4 used for expressing feelings such as doubt. Surprise, or anger... 5 used for ending a discussion or talk...

PHRASES oh well used for accepting a bad situation or disappointment...

very well used for agreeing to something...

well,well used for expressing surprise... 


\section{In OALD:}

Actually...1 used in speaking to emphasize a fact or a comment, or that something is really true...2 used to show a contrast between what is true and what somebody believes...3 used to correct somebody in a polite way...4 used to get somebody's attention, to introduce a new topic or to say something that somebody may not like, in a polite way....

Well... 1 used to express surprise, anger, or relief...7 used to mark the end of a conversation...IDM Well I never 'did' (old fashioned) used to express surprise...

The two dictionaries mention that actually is used for emphasis. MEDAL mentions that it is used to emphasize that something is surprising, and OALD states that it is used to emphasize a fact or a comment. Moreover, OALD states that it is used to politely correct somebody. MEDAL also indicates this but without mentioning that it indicates politeness. It only uses the usage label spoken before this sense. Finally, OALD also includes that it is used when introducing a new topic, and to get somebody's attention. So, again the two dictionaries differ in the pragmatic information included.

As for well, the two dictionaries mention that it is used to express feelings of anger, surprise, etc, as well as for ending a conversation. They also include some phrases in which well is used, such as Well, well in MEDAL, and Well, I never did in OALD. Such phrases are part of the pragmatic information at the sentence level as will be discussed.

\section{(5.1.3) Hedges}

The entries of presumably and probably are taken as examples in the two analysed dictionaries.

\section{In MEDAL:}

Presumably...used for saying that you think something is true based on what you know, although you are not really certain...

Probably...used for saying that you think something is likely...

In OALD:

Presumably ... used to say that you think that something is probably true....

Probably... used to say that something is likely to happen or to be true....

Both dictionaries indicate that presumably is used when one thinks something is probably true, and the same applies to probably when one thinks something is likely to happen. 


\section{(5.1.4) Speech Act Verbs}

Agree and Apologize are two well-known speech act verbs. Therefore, they are taken as examples of this category of verbs in the two dictionaries in question.

\section{In MEDAL:}

Agree... 1... to have the same opinion as someone else..

2 ...to say that you will do something that someone else wants or suggests... If two pieces of information agree, they are the same or suggest the same thing..

\section{Get it right: agree}

When you want to say that you approve of something or think it is the right thing to do, use the pattern 'agree with something' (not 'agree something')

Most Hong Kong women do not agree abortion.

Most Hong Kong women do not agree with abortion...

Agree is rarely used with a direct object. In this use, it means ' to decide something together' and it is mainly used when talking about official decision-making bodies and organizations.

Yesterday management and unions agreed to pay deal.

Ministers met to agree a strategy for tackling climate change.

Ways of expressing agreement
That's right/You're right/ I Know
Exactly/Absolutely/I couldn't agree more
You can say that again/ You're telling me
Why not?
I suppose so/I guess so
Examples
'It's supposed to be a very good school' 'That's
right. They get great results.' ...
'We'll have to get some new tyres.' 'I suppose/
I guess so. But it will be expensive.

used when agreeing with someone

used for saying that you completely agree with someone

a more informal way of saying that you completely agree with someone

used when agreeing with a suggestion someone has made

used when you agree that someone is right, but you are not happy with the situation 
Apologize...to tell someone that you are sorry for doing something wrong or for causing a problem...

\section{Ways of apologizing \\ Sorry/ I'm sorry}

I do apologize for...

Excuse me

I beg your pardon

I/We owe you an apology

Please accept my/our apologies

I / We regret...

Examples

I'm sorry I'm late, Amy. I missed

the train...

We regret to announce that tonight's performance of 'La

Traviata' has been cancelled.

Ways of accepting an apology

That's quite all right/ There's no need to apologize

No Problem

\section{Examples}

'I'm sorry I'm late.' 'That's quite all right I've only been waiting for a minute.'...

'I'm sorry I can't help you' 'No problem, I'll ask Rory.' the usual way of apologizing to someone you know well

a more polite and formal way of apologizing, used especially when you feel responsible for something that someone else has done

used when apologizing for something you did accidentally a more formal way of apologizing for something you did accidentally used when you realize you have treated someone badly, for example by blaming them for something that is not their fault

used when making a written or formal apology

used when making an apology in an official announcement used when telling someone that you do not mind what they have done used when telling someone you know well that you do not mind what they have done.

\section{In OALD:}

Agree...SHARE OPINION...1...to have the same opinion as somebody, to say that you have the same opinion...

SAY YES...3 ...to say "yes"; to say that you will do what somebody wants...

DECIDE 4 to decide with somebody else to do something or to have something...

Apologize...to say that you are sorry for doing something wrong or causing a problem....

Concerning the verb agree, the two dictionaries state some of its meanings. However, MEDAL is better than OALD as it has two usage notes boxes. The first explains when to use the verb agree and the second explains ways of expressing agreement as well as some example sentences.

As for the verb apologize, the two dictionaries indicate that it is used when one is sorry for doing something wrong. However, MEDAL goes beyond OALD as it has a usage note in a separate usage note box 
entitled "Ways of Apologizing" Beside each way, the dictionary states when it is used. This is followed by example sentences that show the use of some ways of apologizing.

\section{(5.1.5) Modal Verbs}

The two modal verbs can and may are taken as examples of modal verbs in the two dictionaries in question.

\section{In MEDAL:}

Can ...

Can is usually followed by an infinitive without 'to'...

There is no perfect tense of can, so has/have been

able is used: I haven't bee able to phone my parents

7 used in requests, offers etc Spoken used in requests or when offering or suggesting something...

9 used for expressing surprise [usually in negatives or questions] mainly spoken used when you want to emphasize how surprised or shocked you are...

May...

May is usually followed by an infinitive without 'to'...

I may go to London next week.

3 used in polite requests or offers spoken used when making a polite request or offer...

4 used in polite remarks or suggestions spoken used when making a polite remark or suggestion...

6 used for expressing a wish formal used for expressing a hope or wish.

Both may and might are used for expressing that idea that perhaps something is true... Might I make a suggestion?

\section{In OALD:}

Can ...

\section{WHICH WORD?}

Can. may

Can and cannot (or can't) are the most common words used for asking for, giving or refusing permission... You can't park your car there.

May (negative may not) is used as a polite and a fairly formal way to ask for or give permission... The form mayn't is almost never used in modern English. 
5 (informal) used to ask permission to do something.

6 (informal) used to ask somebody to help you...

8 used to express doubt or surprise...

May... 3 (formal) used to ask or give permission...

4 (formal) used as a polite way of making a comment, asking a question, etc...

5 (formal) used to express wishes and hopes...

6 (formal) used to say what the purpose of something is...

The two dictionaries mention in separate senses some pragmatic information concerning the modal verb can. MEDAL states that it is used in offers and requests, and to express doubt or surprise. It labels theses uses as spoken. There is also a usage note box that indicates some grammatical information about can, such as it is followed by an infinitive without 'to' and that it does not have a perfect tense. As for OALD, it states that can is used to ask for permission, to ask for help, and to express doubt or surprise. It labels some usages as informal as senses (5) and (6).

As for may, MEDAL indicates some pragmatic information about it, such as it is used for polite requests, polite remarks, and to express hopes and wishes. The dictionary also uses labels such as spoken for senses (3) and (4) and formal for sense (6). There are also two usage notes. The first is at the beginning of the entry about the grammar of this modal verb. The second is at the end of the entry about the difference between may and might. OALD also states some pragmatic information, such as it is used to make polite comments, to ask polite questions, to ask for permission, and to express wishes and hopes. The dictionary also uses the label formal. In the reference section, there is a section about modal verbs and their uses, such as "to express ability" one can use modals as can, could, be able to.

\section{(5.1.6) Context Makers}

A dictionary must be descriptive, and should record different styles. To do this, labels can be used. These labels can refer to a whole entry or a given sense in an entry, or a synonym (Svensen, 1993:181-82). The two dictionaries use different usage labels to mark the contexts in which different words are used. MEDAL uses labels that indicate style as formal, informal, technical field as music, linguistics, and geographical labels as BrE, AmE. OALD also uses technical usage labels as medical, style labels as humorous, formal, impolite, and geographical labels as American and British English. The following are examples of some headwords that are contextually marked in the two dictionaries: 
In MEDAL:

Fire department (American)

Fire brigade (British)

Glitz (informal)

Loquorious (formal)

Maleware (computing)

Memory stick (Trademark)

Operetta (music)

In OALD:

Conjoined twin (technical)

Derring- do (old-fashioned, humorous)

Lethal (figurative)

Memory stick (computing)

Mensch ( NAmE, informal)

Plea (formal. Law)

Prim (disapproving)

Rat pack (BrE, disapproving)

\section{(5.2) Pragmatic Information at the Sentence Level}

Pragmatic information at the sentence level includes the speech acts with which a given phrase or utterance is associated, and how they should be used. Pragmatic information at this level is illustrated in a separate section after the entry. MEDAL uses the title phrases, and OALD uses the title idiom. This is clear in the entries of mercy and hate as explained below:

\section{In MEDAL:}

Hate...PHRASES hate somebody's guts informal to hate someone very much I hate to bother/interrupt/ trouble, etc...you spoken a polite way of saying you are sorry for interrupting someone or asking them for something...

I hate to say/ admit or I hate to tell you used for showing that you are sorry about what you are going to say, or because you think it is unpleasant or you wish it is not true...

I hate to think spoken used for emphasizing that you do not want to think about something because it is unpleasant or upsetting...

I hate (for) somebody something or I'd hate the see somebody/something do something used for saying that a particular situation or event would make you feel unhappy....

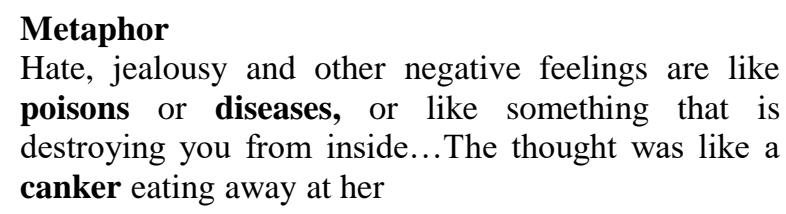

Mercy... PHRASES at the mercy used in a situation that is controlled by someone or something with the power to harm you...

be thankful/ grateful for small mercies used to say that you should be grateful for something good that has happened because it is one of the few good things in a bad situation... 
have mercy (on something) to treat someone in a kind way instead of a cruel way. leave somebody to the (tender) mercies of humorous to put someone in a situation where they could be treated in a strict or unfair way by someone or something...

what a mercy British It's a mercy British used for saying that it is lucky that a situation is not as bad as it could have been...

throw yourself on somebody's mercy mainly literary used to ask someone in authority to treat you in a kind way.

\title{
In OALD:
}

Hate...I hate to think what would have happened if you hadn't been there...I hate to say it, but I don't think their marriage will last...IDM hate somebody's guts (informal) to dislike somebody very much

\begin{abstract}
Mercy... IDM at the mercy of somebody/something not to be able to stop somebody/something harming you because they have the power or control over you...leave somebody/something to the mercy/mercies of somebody/something to leave somebody/something in a situation that may cause them to suffer or to be treated badly throw yourself on somebody's mercy (formal) to put yourself in a situation where you must rely on somebody to be kind to you and not harm or punish you....
\end{abstract}

As for the entry of hate, MEDAL lists some spoken phrases in which it is used, such as hate somebody's gut and I hate to bother/interrupt/trouble you with an explanation of their meaning. In the explanation of the latter phrase, the dictionary clarifies that it is usually associated with polite attitude. There are other phrases, such as I hate to think, and I hate for $s b / s t h$ to do sth. OALD does not include as many phrases and idioms as MEDAL. The former also includes the idiom hate somebody's gut, and labels it as informal. It includes other phrases as I hate to say it, and I hate to think as part of the example sentences. Thus, it is not clear for users that these are phrases.

In the entry of mercy, MEDAL states, in a separate section entitled Phrases, a number of phrases in which it is used as at the mercy and be thankful/grateful for small mercies followed by explanations of their meaning. OALD also states, in a section entitled Idioms after the entry, some idioms in which mercy is used together with explanations of their meaning, such as leave sb/sth to the mercy/mercies of $s b / s t h$, and at the mercy of sb/sth.

It is clear that pragmatic information at the sentence level could be presented in the form of phrases and idioms listed in separate senses in the entries themselves, each according to its meaning, or in a separate section at the end of the entry.

\section{(5.3) Pragmatic Information at the Discourse Level}

In MEDAL and OALD, there is no information neither about topic choice nor cultural background. Also, there are not any language notes about speech act pairs. However, in MEDAL in the entries of offer and permission, there are two usage notes sections. The former is about "ways 
of offering sth to sb and of accepting or refusing an offer," and the latter is about "ways of asking and giving permission," as indicated below:

Offer...

Ways of offering something to someone and of accepting or refusing an offer

Would you like...?

Do you want...?

Would you care for...?

How would you like...? / What would you say to...?

Do you fancy...? / How about...?

Who wants...?

Can I get you...?

What will you have?

Yes, please/ Thank you/ Thanks (very much)

No, thank you /Thank you but.../ No, thanks

\section{I couldn't}

Not for me, thanks

\section{Examples}

the most usual way of offering something to someone or inviting them to do something

a more informal way of offering something to someone

a more formal way of asking someone if they would like something

used for offering someone something that you think they will enjoy

an informal way of asking someone if they would like something used for offering something to a group of people

used especially when offering someone food or drink

used when asking someone what they would like, especially in a restaurant, bar, or café

used as a polite way of accepting something that someone has offered you

used for politely refusing something that someone has offered you

used for politely refusing food or drink that someone has offered you an informal way of politely refusing food or drink that someone has offered you

Would you like a magazine to read while you're waiting?' 'Thanks very much - that would be great'.. 'Would you like a salad with your pizza?' 'Not for me, thanks' 


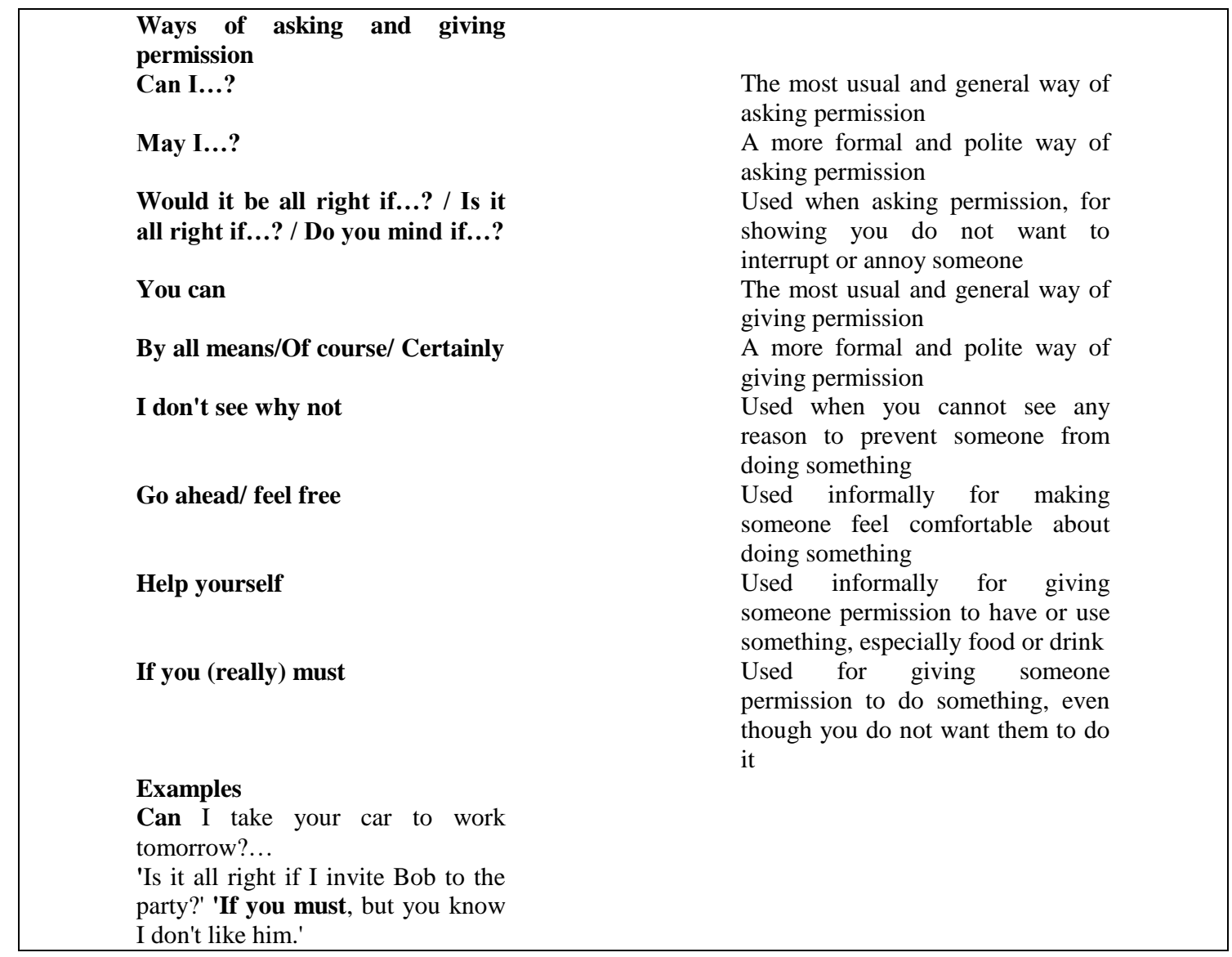

In OALD there is no such information.

It can be observed from the two entries above that MEDAL lists in the entry of offer, first and second parts speech act pairs as part of the example sentences, but not in the list of "refusing an offer". The same happens in the entry of permission. However, in the example sentences, only the first part of the speech act pair is found. Therefore, the dictionary is inconsistent in this respect. For some second part speech act pairs the answer is not fixed as it is contextually dependent. These are called "approximate speech act pairs". No speech act pairs are found in the entries of some verbs as praise and greet in the two dictionaries in spite of their being some of the commonly used speech act pairs.

\section{(6) Conclusion}

Different kinds of pragmatic information at three levels of analysis, namely lexical, sentential, and discourse is found in the two analysed dictionaries. There are a number of ways in which pragmatic information is included in the entries. For example, it can be found as part of the definitions or by using phrases as "used politely to..." Pragmatic information is also found in separate usage notes to explain various language usage points, such as "ways of expressing agreement, offers, 
etc." Another way of stating pragmatic information in the entries of some headwords is in a separate section entitled "phrases" or "idioms". In MEDAL, there are language reference sections about various language topics as "modal verbs" and "pragmatic information". It has also been observed that the two dictionaries are inconsistent in the pragmatic information they present at the three above mentioned linguistic levels. This can be due to the fact that the two dictionaries use different corpora. MEDAL uses the World English Corpus, while OALD uses the British National Corpus, the Oxford Corpus Collection, and the Oxford Reading Programme for language research. In addition, MEDAL includes a language awareness section in the middle part of the dictionary, where a number of linguistic issues are explained, and one of them is about the presentation of pragmatic information in the dictionary. In OALD, there is also a separate reference section in the back matter of the dictionary where some linguistics topics are explained, such as modal verbs conditionals, the passive voice, etc. However, nothing is indicated about the treatment of pragmatic information in the dictionary. So, a language reference section must be included. In fact, a language reference section about the presentation of pragmatic information must be included in all dictionaries whether in the front, middle, or back matters to clarify to users this important linguistic aspect.

It can be noticed that topic choice and cultural background are not explicitly indicated. However, usage labels beside some headwords or senses, such as taboo and disapproving, indicate that such senses are not accepted in the English language culture. So, it is inappropriate to use them. In the two dictionaries under investigation, there are not any elaborations about the social situations and topics that such headwords or senses could occur, so learners could avoid such embarrassing situations and topics. In fact, a dictionary should be descriptive, and should inform users about the attitudes of a given society towards particular language forms and uses (Al-Kasimi, 1977: 85).

To overcome some of the problems in presenting and finding pragmatic information in the two analysed English monolingual learners' dictionaries, there should be a bidirectional cross-reference between the language reference section about pragmatic information and the entries of headwords where such information is found. 


\section{$\underline{\text { References }}$}

Al-kasimi, Ali M. (1977). Linguistics and Bilingual Dictionaries. Indiana: Indiana University Publications.

Azar, Betty Schrampfer (1989). Understanding and Using English Grammar, $2^{\text {nd }}$ Edition. New Jersey: Prentice Hall Regents.

Brinton, L.J. (1996). Pragmatic Markers in English. New York: Mouton de Gutyer

Burthanov, Igor (2003). Pragmatic Specifications: Usage, Indications, Labels, Examples, Dictionaries of Style, Dictionaries of Collocations. In Pictvan Sterkenburg (ed.), A Practical Guide to Lexicography. Philadelphia: John Benjamins.

Hartmann, R.R.K. (1983). On specifying Context: How to Label Contexts and Varieties of Usage. In R.R.K. Hartmann (ed), Lexicography: Principles and Practice. London: Academic Press Inc. Ltd.

Hartmann, R.R.K. \& James, G (2000). Dictionary of Lexicography. Beijing: Foreign Language Teaching and Research Press.

Hornby, A.S. (2010). Oxford Advanced Learners' Dictionary ( $7^{\text {th }}$ ed.) Sally Weheimer et al. (eds) Oxford: OUP.

Landau, Sidney (1991). Dictionaries: The Art and Craft of Lexicography. Cambridge: CUP.

Levinson, S. (1983). Pragmatics. Cambridge : CUP.

Lyons, John (1979). Semantics, vol.2. Cambridge: CUP.

McArthur, Tom (1998). Oxford Concise Companion to the English Language. Oxford: OUP.

Nobuyuki, Hagasi (1981). Dictionary and Pragmatics. In Chi Shu Yan, 8(2): $140-48$.

Richards, Jack C, (1996). Longman Dictionary of Language Teaching and Applied Linguistics. Essex: Longman. 
Rundell, Michael (ed.) (2007). Macmillan English Dictionary for Advanced Learners ( $2^{\text {nd }}$ ed.). Oxford: Macmillan Publishers Limited.

Svensen, Bo (1993). Practical Lexicography: Principles and Methods of Dictionary-Making. Oxford: OUP.

Quian, Houshery (1995). Pragmatic Analysis and Bilingual Dictionaries. In Chi Shu Yan, 89 (1): 11-22.

Yule, George (2008). Pragmatics. Oxford: OUP. 